\title{
Modification Adomian Decomposition Method for solving Seventh OrderIntegro-Differential Equations
}

\author{
Samaher M. Yassien \\ Department of MathematicsCollege of Education for Sciences pure \\ Baghdad University,Iraq
}

\begin{abstract}
In this paper, a method based on modified adomian decomposition method for solving Seventh order integro-differential equations (MADM). The distinctive feature of the method is that it can be used to find the analytic solution without transformation of boundary value problems. To test the efficiency of the method presented two examples are solved by proposed method.
\end{abstract}

Keyword: Adomian decomposition method; boundary-value problems; integro-differential equation

\section{Introduction}

An analytical method called the Adomian decomposition method (ADM) proposed by Adomian [1] aims to solve frontier nonlinear physical problems. It has been applied to a wide class of deterministic and stochastic problems, linear and nonlinear, in physics, biology and chemical reactions etc. For nonlinear models, the method has shown reliable results in supplying analytical approximations that converge rapidly [2].The Adomian decomposition method (ADM) [3,4] has been efficiently used to solve linear and nonlinear problems such as differential equations and integral equations. The methodprovides the solution as an infinite series in which each term can be easily determined. The rapid convergence of the series obtained by this method is horoughly discussed byCherruault et al. [5]. Recently, Wazwaz [6] proposed a reliable modified techniqueof $\mathrm{ADM}$ that accelerates the rapid convergence of decomposition series solution. The modified decomposition needs only a slight variation from the standard decompositionmethod. Although the modified decomposition method may provide the exact solution by using two iterations only and sometimes without using the so-called Adomian polynomials, its effectiveness is based on the assumption that the function $f$ can be divided into two parts, and thus the success of themodifiedmethod depends on the proper choice of $f 1$ and $f 2$.The $\operatorname{ADM}[7,8,9]$ is a well-known systematic method for solving linear and nonlinear equations, including ordinary differential equations,partial differential equations, integral equations and integro-differential equations. The method permits us to solve both nonlinearinitial value problems and boundary value problems. The method is well known, and several advanced progresses are conducted inthis regard.

\section{Description of the Modification Adomian decomposition method}

Since the beginning of the 1980s, theAdomian decompositionmethod has been applied to a wide class of integral equations. To illustrate the procedure, consider the following Volterraintegral equations of the second kind given by

$$
\mathrm{L}(\mathrm{y}(x))=(x)+\lambda \int_{\mathrm{a}}^{\mathrm{x}} \mathrm{K}(\mathrm{x}, \mathrm{t})(\mathrm{R}(\mathrm{y}(t))+N(\mathrm{y}(t))) \mathrm{d} t, \lambda=10,
$$

where the kernel $K(x, t)$ and the function $f(x)$ are given realvalued functions, $\lambda$ is a parameter, $\mathrm{R}(\mathrm{y}(x))$ and $N(\mathrm{y}(x))$ are linear and nonlinear operators of $\mathrm{y}(x)[10]$, the differential operator $\mathrm{L}(\mathrm{y}(x))$ is the highest order derivative in the equation, respectively, Then, we assume that $\mathrm{L}$ is invertible byusing the given conditions and applying the inverse operator $\mathrm{L}^{-1}$ to both sides of (1), we get the following equation:

$$
\mathrm{y}(x)=\psi_{0}+\mathrm{L}^{-1} f(x)+\mathrm{L}^{-1}\left(\lambda \int_{\mathrm{a}}^{\mathrm{x}} \mathrm{K}(\mathrm{x}, \mathrm{t})(\mathrm{R}(\mathrm{y}(t))+N(\mathrm{y}(t))) \mathrm{d} t\right), \lambda=0,
$$

where the function $\psi_{0}$ is arising from integrating the source term from applying the given conditions which are prescribed. And so on the Adomian decomposition method admits the decomposition of y into an infinite series of components [11]

$$
\mathrm{y}(\mathrm{x})=\sum_{\mathrm{n}=0}^{\infty} \mathrm{y}_{\mathrm{n}}(\mathrm{x})(3)
$$

Moreover, the Adomian decomposition method identifies the nonlinearterm $N(\mathrm{y}(x))$ by the decomposition series 


$$
\mathrm{N}(\mathrm{y})=\sum_{\mathrm{n}=0}^{\infty} \mathrm{A}_{\mathrm{n}}(\mathrm{x})(4)
$$

WhereAnis the so-called Adomian polynomials, whichcan be evaluated by the following formula [12, 13]:

$$
A n=\frac{1}{\mathrm{n} !} \frac{\mathrm{d}}{\mathrm{d} \lambda^{\mathrm{n}}} \stackrel{\mathrm{n}}{\mathrm{N}}\left(\sum_{\mathrm{i}=0}^{\mathrm{n}} \lambda^{\mathrm{i}} \mathrm{y}_{\mathrm{i}}\right) \quad, \quad n=0,1,2, \ldots(5)
$$

Substituting (3) and (4) into both sides of (2) gives

$$
\sum_{n=0}^{\infty} y_{n}(x)=\psi_{0+} L^{-1} f(x)+L^{-1}\left(\lambda \int_{a}^{x} K(x, t)\left[R\left(\sum_{n=0}^{\infty} y_{n}(t)\right)+\sum_{n=0}^{\infty} A_{n}(t)\right] d t\right),
$$

The various components $\mathrm{y}_{\mathrm{n}}$ of the solution $\mathrm{y}$ can be easily determined by using the recursive relation $\mathrm{Y}_{0}=\psi_{0+} \mathrm{L}^{-1} \mathrm{f}(\mathrm{x})$

$$
\mathrm{Y}_{\mathrm{k}+1}=\mathrm{L}^{-1}\left(\lambda \int_{\mathrm{a}}^{\mathrm{x}} \mathrm{K}(\mathrm{x}, \mathrm{t})\left[\mathrm{R}\left(\sum_{\mathrm{n}=0}^{\infty} \mathrm{y}_{\mathrm{k}}(\mathrm{t})\right)+\sum_{\mathrm{n}=0}^{\infty} \mathrm{A}_{\mathrm{k}}(\mathrm{t})\right] \mathrm{d} t\right), \text { fork } \geq 0 .
$$

Consequently, the first few components can be written as

$$
\begin{aligned}
& \mathrm{Y}_{0}={ }_{0+} \mathrm{L}^{-1} \mathrm{f}(\mathrm{x}), \\
& \mathrm{Y}_{1=} \mathrm{L}^{-1}\left(\int_{\mathrm{a}}^{\mathrm{x}} \mathrm{K}(\mathrm{x}, \mathrm{t})\left[\mathrm{R}\left(\sum_{\mathrm{n}=0}^{\infty} \mathrm{y}_{0}(\mathrm{t})\right)+\sum_{\mathrm{n}=0}^{\infty} \mathrm{A}_{0}(\mathrm{t})\right] \mathrm{d} t\right), \\
& \mathrm{Y}_{2}=\mathrm{L}^{-1}\left(\lambda \int_{\mathrm{a}}^{\mathrm{x}} \mathrm{K}(\mathrm{x}, \mathrm{t})\left[\mathrm{R}\left(\sum_{\mathrm{n}=0}^{\infty} \mathrm{y}_{1}(\mathrm{t})\right)+\sum_{\mathrm{n}=0}^{\infty} \mathrm{A}_{1}(\mathrm{t})\right] \mathrm{d} t\right),
\end{aligned}
$$

where the Adomian polynomial can be evaluated by (4),Having determined the components $Y_{n}, n \geq 0$, the solution y in a series form follows immediately. As stated before, the series may be summed to provide the solution in a closed form. We can apply modification by assuming that the function $\mathrm{F}$ can be written as

$$
\mathrm{F}=\psi_{0+} \mathrm{L}^{-1} \mathrm{f}(\mathrm{x}),(9)
$$

The components $Y_{n}$ are determined by using the following relation:

$$
\begin{gathered}
\mathrm{Y}_{0}=\mathrm{F},(10) \\
\mathrm{Y}_{\mathrm{k}+1} \mathrm{~L}^{-1}\left(\int_{\mathrm{a}}^{\mathrm{x}} \mathrm{K}(\mathrm{x}, \mathrm{t})\left[\mathrm{R}\left(\sum_{\mathrm{n}=0}^{\infty} \mathrm{y}_{\mathrm{k}}(\mathrm{t})\right)+\sum_{\mathrm{n}=0}^{\infty} \mathrm{A}_{\mathrm{k}}(\mathrm{t})\right] \mathrm{d} t\right) \text {, for } \mathrm{k} \geq 0(11)
\end{gathered}
$$

From the above equations, we observe that the component $Y_{0}$ is identified by theFunction $F$. the modified Adomian decomposition method will minimize the volume of calculations, we split the function $\mathrm{F}$ into two parts, $F_{0}$ and $F_{1}$. Let the function be as follows:

$$
\mathrm{F}=\mathrm{F}_{0}+\mathrm{F}_{1}(12)
$$

Under this assumption, we have a slight variation for components $Y_{0}$ and $Y_{1}$, where $F_{0}$ assigned to $Y_{0}$ and $F_{1}$ is combined with the other terms in (10) to assign $Y_{1}$. The modified recursive algorithm is as follows:

$$
\left.\begin{array}{c}
\mathrm{y}_{0}=\mathrm{F}_{0}, \\
\mathrm{y}_{1}=\mathrm{F}_{1}+\mathrm{L}^{-1}\left(\lambda \int_{\mathrm{a}}^{\mathrm{x}} \mathrm{K}(\mathrm{x}, \mathrm{t})\left[\mathrm{R}\left(\sum_{\mathrm{n}=0}^{\infty} \mathrm{y}_{0}(\mathrm{t})\right)+\sum_{\mathrm{n}=0}^{\infty} \mathrm{A}_{0}(\mathrm{t})\right] \mathrm{dt}\right), \\
\mathrm{y}_{\mathrm{K}+1}=\mathrm{L}^{-1}\left(\lambda \int_{\mathrm{a}}^{\mathrm{x}} \mathrm{K}(\mathrm{x}, \mathrm{t})\left[\mathrm{R}\left(\sum_{\mathrm{n}=0}^{\infty} \mathrm{y}_{\mathrm{k}}(\mathrm{t})\right)+\sum_{\mathrm{n}=0}^{\infty} \mathrm{A}_{\mathrm{k}}(\mathrm{t})\right] \mathrm{dt}\right),
\end{array}\right\}(13)
$$

for $\mathrm{k} \geq 1$.

However, the nonlinear term $\mathrm{F}(\mathrm{y})$ can be expressed by infinite series of the so-called Adomian polynomials $A_{n}$ given in the form

$$
\mathrm{F}(\mathrm{y})=\sum_{\mathrm{n}=0}^{\infty} \mathrm{An}\left(\mathrm{y}_{0}, \mathrm{y}_{1}, \mathrm{y}_{2}, \ldots, \mathrm{y}_{\mathrm{n}}\right)
$$


There are several rules that are needed to follow for Adomian polynomials of nonlinear operator $\mathrm{F}(\mathrm{y})$ :

$\mathrm{A}_{0}=\mathrm{F}\left(\mathrm{y}_{0}\right)$,

$$
\mathrm{A}_{1}=\mathrm{y}_{1} \mathrm{~F}^{\prime}\left(\mathrm{y}_{0}\right),(15)
$$

$\mathrm{A}_{2}=\mathrm{y}_{2} \mathrm{~F}^{\prime}\left(\mathrm{y}_{0}\right)+\frac{1}{2 !} \mathrm{y}_{1}^{2} \mathrm{~F}^{\prime \prime}\left(\mathrm{y}_{0}\right)$

and so on; see [1], then substituting (15) into (14) gives

$$
\mathrm{F}(\mathrm{y})=\mathrm{A}_{0+} \mathrm{A}_{1+} \mathrm{A}_{2+\ldots(16)}
$$

To illustrate the applicability and effectiveness of the method, we presented two numerical examples .

\section{Example1[14]:-}

\section{Application for Linear and Nonlinearintegro-differential equations}

Consider the following linearintegro-differential equation:

$$
\mathrm{y}^{(\mathrm{vii})}(\mathrm{x})=2-8 \mathrm{e}^{\mathrm{x}}+\int_{0}^{\mathrm{x}} \mathrm{y}(\mathrm{t}) \mathrm{dt}, \quad 0 \leq \mathrm{x} \leq 1
$$

withthe boundary conditions:

$y(0)=1, y^{\prime}(0)=0, y^{\prime \prime}(0)=-1, y^{\prime \prime \prime}(0)=-2$,
$y(1)=0, y^{\prime}(1)=-e, y^{\prime \prime}(1)=-2 e$

theexactsolution is $y(x)=(1-x) e^{x}$.

Equation (18) can be rewritten in operator form as follows:

$$
\operatorname{Ly}(x)=2-8 e^{x}+\int_{0}^{x} y(t) d t, \quad 0 \leq x \leq 1
$$

Operating with sevenfold integral operator $\mathrm{L}^{-1}$ on (19) and using the boundary conditions at $\mathrm{x}=0$, we obtain the following equation:

$$
y(x)=1-\frac{1}{2 !} x^{2}-\frac{2}{3 !} x^{3}+\frac{A}{4 !} x^{4}+\frac{B}{5 !} x^{5}+\frac{C}{6 !} x^{6}+L^{-1}\left(2-8 e^{x}\right)+L^{-1}\left(\int_{0}^{t} y(t) d t\right)
$$

Then, determine the constants

$\mathrm{y}^{(4)}(0)=\mathrm{A}, \mathrm{y}^{(5)}(0)=\mathrm{B}, \mathrm{y}^{(6)}(0)=\mathrm{C}$.

Substituting the decomposition series (3) for $y(x)$ into (20) yields

$\sum_{n=0}^{\infty} y_{n}(x)=1-\frac{1}{2 !} x^{2}-\frac{2}{3 !} x^{3}+\frac{A}{4 !} x^{4}+\frac{B}{5 !} x^{5}+\frac{C}{6 !} x^{6}+L^{-1}\left(2-8 e^{x}\right)+L^{-1}\left(\int_{0}^{t} y(t) d t\right)(21)$

Then, we split the terms into two parts which are assigned to $\mathrm{y}_{0}(\mathrm{x})$ and $\mathrm{y}_{1}(\mathrm{x})$ that are notincluded under $\mathrm{L}^{-1}$ in (21). We can obtain the following recursive relation:

$$
\begin{gathered}
\mathrm{y}_{0}(\mathrm{x})=\left(1-\frac{1}{2} \mathrm{x}^{2}\right) \\
\mathrm{y}_{1}(\mathrm{x})=-\frac{2}{3 !} \mathrm{x}^{3}+\frac{\mathrm{A}}{4 !} \mathrm{x}^{4}+\frac{\mathrm{B}}{5 !} \mathrm{x}^{5}+\frac{\mathrm{C}}{6 !} \mathrm{x}^{6}+\mathrm{L}^{-1}\left(2-8 \mathrm{e}^{\mathrm{x}}\right)+\mathrm{L}^{-1}\left(\int_{0}^{\mathrm{t}} \mathrm{y}(\mathrm{t}) \mathrm{dt}\right)
\end{gathered}
$$

To determine the constants A,Band C, we use the boundary conditions in (18) at $x=1$ on the two-term approximant $\varphi_{2}$, where

$$
\varphi_{2}=\sum_{\mathrm{k}=0}^{1} \mathrm{y}_{\mathrm{k}},(23)
$$


The coefficients A,BandC, were obtained by using Matlab with boundary conditions at $\mathrm{x}=1$ in (18) given

$\mathrm{A}=-2.999889405606837, \mathrm{~B}=-4.001335322252864, \mathrm{C}=-4.994950164651542$.

Then we get the series solution as follows:

$\mathrm{Y}(\mathrm{x})=8 \mathrm{x}-8 \mathrm{e}^{\mathrm{x}}+3.5 \mathrm{x}^{2}+\mathrm{x}^{3}+0.2083379414330485 \mathrm{x}^{4}+0.0333222056478928 \mathrm{x}^{5}+4.173680326872859 \mathrm{x}^{6} \mathrm{x}$ $10^{-3}+3.968253968253968 \mathrm{x}^{7} \times 10^{-4}-8.267195767195767 \mathrm{x}^{8} \times 10^{-7}\left(\mathrm{x}^{2}-30\right)+9$.

\section{Example 2 [14] :-}

Consider the followingnonlinear integro-differential equation:

withthe boundary conditions:

$$
\mathrm{y}^{(\mathrm{vii})}(\mathrm{x})=1+\int_{0}^{\mathrm{x}} \mathrm{e}^{-\mathrm{x}} \mathrm{y}^{2}(\mathrm{t}) \mathrm{dt}, \quad 0 \leq \mathrm{x} \leq 1(25)
$$

$y(0)=1, y^{\prime}(0)=1, y^{\prime \prime}(0)=1, y^{\prime \prime \prime}(0)=1$,
$y(1)=e, y^{\prime}(1)=e, y^{\prime \prime}(1)=e$.

$$
\text { the exact solution is } y(x)=e^{x} \text {. }
$$

Equation (25) can be rewritten in operator form as follows:

$$
\operatorname{Ly}(x)=1+\int_{0}^{x} e^{-x} y^{2}(t) d t, \quad 0 \leq x \leq 1,(27)
$$

Operating with sevenfold integral operator $\mathrm{L}^{-1}$ on (27) and using the boundary conditions at $\mathrm{x}=0$, we obtain the following equation:

$$
y(x)=1+x+\frac{1}{2 !} x^{2}+\frac{1}{3 !} x^{3}+\frac{A}{4 !} x^{4}+\frac{B}{5 !} x^{5+} \frac{C}{6 !} x^{6}+L^{-1}\left(\int_{0}^{x} e^{-x} y^{2}(t) d t\right)
$$

Then, determine the constants

$$
\mathrm{y}^{(4)}(0)=\mathrm{A}, \mathrm{y}^{(5)}(0)=\mathrm{B}, \mathrm{y}^{(6)}(0)=\mathrm{C}
$$

Substituting the decomposition series (3) for $y(x)$ and the series of polynomials (4) into (28) yields

$$
\sum_{n=0}^{\infty} y_{n}(x)=1+x+\frac{1}{2 !} x^{2}+\frac{1}{3 !} x^{3}+\frac{A}{4 !} x^{4}+\frac{B}{5 !} x^{5+C} \frac{C}{6 !} x^{6}+L^{-1}\left(\int_{0}^{x} e^{-x} \sum_{n=0}^{\infty} A_{n}(x) d t\right)
$$

Then, we split the terms into two parts which are assigned to $\mathrm{y}_{0}(\mathrm{x})$ and $\mathrm{y}_{1}(\mathrm{x})$ that are notincluded under $\mathrm{L}^{-1}$ in (29). We can obtain the following recursive relation:

$$
\begin{gathered}
\mathrm{y}_{0}(\mathrm{x})=1, \\
\mathrm{y}_{1}(\mathrm{x})=\mathrm{x}+\frac{1}{2 !} \mathrm{x}^{2}+\frac{1}{3 !} \mathrm{x}^{3}+\frac{\mathrm{A}}{4 !} \mathrm{x}^{4}+\frac{\mathrm{B}}{5 !} \mathrm{x}^{5+} \frac{\mathrm{C}}{6 !} \mathrm{x}^{6}+\mathrm{L}^{-1}\left(\int_{0}^{\mathrm{x}} \mathrm{e}^{-\mathrm{x}} \sum_{\mathrm{n}=0}^{\infty} \mathrm{A}_{0}(\mathrm{x}) \mathrm{dt}\right) \\
\mathrm{y}_{\mathrm{k}+1}=-\mathrm{L}^{-1}\left(\mathrm{y}_{\mathrm{k}}\right), \quad \text { for } \mathrm{k} \geq 1 .
\end{gathered}
$$

To determine the constants A,Band $\mathrm{C}$, we use the boundary conditions in (26) at $\mathrm{x}=1$ on the two-term approximant $\varphi_{2}$, where

$$
\varphi_{2}=\sum_{\mathrm{k}=0}^{1} \mathrm{y}_{\mathrm{k}},(31)
$$

The coefficients A,Band C, are obtained by using Matlab which gives :

$\mathrm{A}=1.001099789026682, \mathrm{~B}=0.9862204404890547, \mathrm{C}=1.055324181428374$.

Then we get the series solution as follows:

$Y(x)=3 x^{2}-7 e^{-x}-x e^{-x}-5 x-0.5 x^{3}+0.1667124912094451 x^{4}-0.008448162995924544 x^{5}+0.002854616918650519 x^{6}$ 
$+0.0001984126984126984 x^{7}+8$.

The approximate solutions of two numerical examples obtained with the help of MADM, in Table 1- 2 respectively. From the numerical results, it is clear that the MADM is more efficient and accurate. The graphical comparison of exact and approximate solutions is shown in Figure 1-2 respectively.

\section{Conclusions}

The objective of this paper is to present a simple method to solve linear and nonlinear seventh order integro-differential equations without discretization, transformation, linearization .Modified adomian decomposition methodgave good agreements and reliable for results. Also this method is useful for finding an accurate approximation of the exact solution .

Table 1: Comparison of numerical results for Example 1

\begin{tabular}{|c|c|c|c|}
\hline $\mathrm{x}$ & Exact solution & MADM & Error MADM \\
\hline 0 & 1.000000000000000 & 1.000000000000000 & 0 \\
\hline 0.1 & 0.994653826268083 & 0.994653826624630 & $3.56547 \mathrm{E}-10$ \\
\hline 0.2 & 0.977122206528136 & 0.977122210789053 & $4.260918 \mathrm{E}-9$ \\
\hline 0.3 & 0.944901165303202 & 0.944901180698329 & $1.5395127 \mathrm{E}-8$ \\
\hline 0.4 & 0.895094818584762 & 0.895094851276987 & $3.2692225 \mathrm{E}-8$ \\
\hline 0.5 & 0.824360635350064 & 0.824360684692413 & $4.9342349 \mathrm{E}-8$ \\
\hline 0.6 & 0.728847520156204 & 0.728847576170160 & $5.6013957 \mathrm{E}-8$ \\
\hline 0.7 & 0.604125812241143 & 0.604125859081428 & $4.6840285 \mathrm{E}-8$ \\
\hline 0.8 & 0.445108185698494 & 0.445108211038539 & $2.5340045 \mathrm{E}-8$ \\
\hline 0.9 & 0.245960311115695 & 0.245960316546181 & $5.430487 \mathrm{E}-9$ \\
\hline 1 & 0 & 0.000000000000002 & $2 . \mathrm{E}-15$ \\
\hline
\end{tabular}

Table 2: Comparison of numerical results for Example 2

\begin{tabular}{|c|c|c|c|}
\hline $\mathrm{x}$ & Exact solution & MADM & Error MADM \\
\hline 0 & 1.000000000000000 & 1.000000000000000 & 0 \\
\hline 0.1 & 1.105170918075648 & 1.105170921586637 & $3.510989 \mathrm{E}-9$ \\
\hline 0.2 & 1.221402758160170 & 1.221402799647473 & $4.1487303 \mathrm{E}-8$ \\
\hline 0.3 & 1.349858807576003 & 1.349858955574768 & $1.47998765 \mathrm{E}-7$ \\
\hline 0.4 & 1.491824697641270 & 1.491825007512418 & $3.09871147 \mathrm{E}-7$ \\
\hline 0.5 & 1.648721270700128 & 1.648721731250776 & $4.60550647 \mathrm{E}-7$ \\
\hline 0.6 & 1.822118800390509 & 1.822119314684251 & $5.14293742 \mathrm{E}-7$ \\
\hline 0.7 & 2.013752707470477 & 2.013753130155561 & $4.22685085 \mathrm{E}-7$ \\
\hline 0.8 & 2.225540928492468 & 2.225541153090809 & $2.24598341 \mathrm{E}-7$ \\
\hline 0.9 & 2.459603111156950 & 2.459603158412758 & $4.7255808-8$ \\
\hline 1 & 2.718281828459046 & 2.718281828459046 & 0 \\
\hline
\end{tabular}

The solution at $\mathrm{Y} 2$

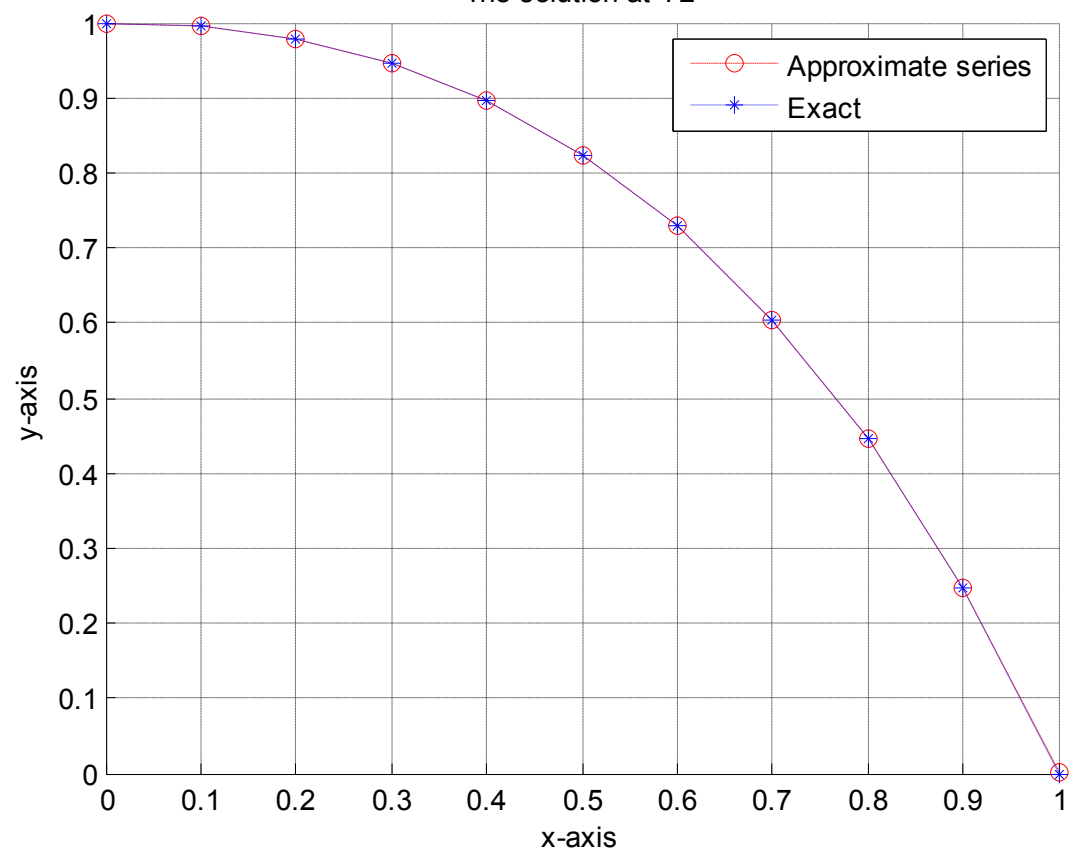

Figure 1: Comparison between the exact and MADM solution of example1. 


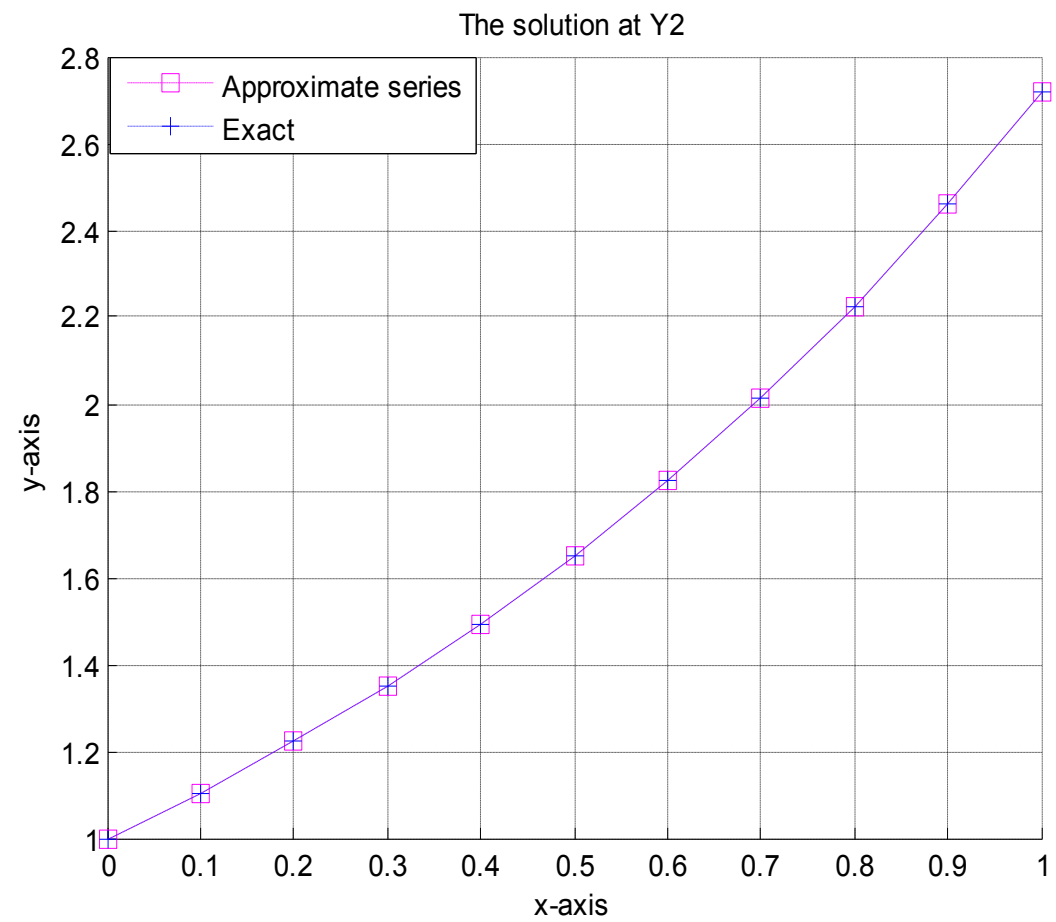

Figure 2: Comparison between the exact and MADM solution of example

\section{References}

[1]. G. Adomian, Solving Frontier Problems of Physics: The Decompositions Method, Kluwer, Boston,(1994).

[2]. W. Chen and Z. Lu, An algorithm for Adomian decomposition method.Appl Math Comput, 159 (2004) $221-235$.

[3]. G. Adomian, “A review of the decomposition method and some recent results for nonlinearequations,"Mathematical and Computer Modelling, vol. 13, no. 7, pp. 17- 43, 1990.

[4]. G. Adomian, Solving Frontier Problems of Physics: The Decomposition Method, vol. 60 of Fundamental Theories of Physics, Kluwer Academic, Dordrecht,TheNetherlands, 1994.

[5]. Y. Cherruault, G. Saccomandi, and B. Some, "New results for convergence of Adomian's method applied to integral equations," Mathematical and ComputerModelling, vol. 16, no. 2, pp. 85-93, 1992.

[6]. A.-M.Wazwaz, "A reliable modification of Adomian decomposition method," AppliedMathematics and Computation, vol. 102, no. 1, pp. 77-86, 1999.

[7]. W . Abdul-Majid, R . Randolph and D. Jun-Sheng," A study on the systems of theVolterra integral forms of the Lane-Emden equations by the Adomiandecomposition method ," MOS subject classification: 34A34; 35C05; 37C10, Published online 21 March 2013 in Wiley Online Library.

[8]. Wazwaz AM. Partial Differential Equations and SolitaryWaves Theory. HEP and Springer: Beijing and Berlin, 2009.

[9]. Rach R. A new definition of the Adomianpolynomials. Kybernetes 2008; 37:910-955.

[10]. B . Roberto, “A New Modification of Adomian Decomposition Method for Volterra Integral Equations of the Second Kind," Department of Mathematics, Faculty of Science, Ningbo University, Ningbo, Zhejiang 315211, China , Volume 2013,Article ID 795015, 7 pages

[11]. H .Waleed, “ Solving nth-Order Integro-Differential Equations Using theCombined Laplace Transform-Adomian Decomposition Method," Department ofMathematics, College of Computer Science and Mathematics, University of Mosul, Mosul, Iraq ,Applied Mathematics, 2013, 4, 882-886.

[12]. A.-M. Wazwaz, "A new algorithm for calculating Adomian polynomials for nonlinear operators," AppliedMathematics and Computation, vol. 111, no. 1, pp. 33-51, 2000.

[13]. E. Babolian and Sh. Javadi, "New method for calculating Adomian polynomials," AppliedMathematics and Computation, vol. 153, no. 1, pp. 253-259, 2004.

[14]. N. S. Jafar and G. A. Fahimeh, "Variational iteration method for solving Seventh order integro-differential equations," Departman of Applied Mathematics, School of Mathematical Sciences, Ferdowsi University of Mashhad, Iran.10-12 March 2012. 